\title{
Effect of Silica Fume on the Pore Structure and Properties of Mortars Exposed to Sulphate Aggressive Media
}

\author{
José Marcos Ortega ${ }^{1,2, *}$, María Dolores Esteban ${ }^{2}$, Mark Williams ${ }^{3}$, Isidro Sánchez ${ }^{1}$ and Miguel \\ Ángel Climent ${ }^{1}$ \\ 1 Departamento de Ingeniería Civil, Universidad de Alicante, Ap. Correos 99, 03080, Alacant/Alicante, \\ Spain; isidro.sanchez@ua.es (I.S.); ma.climent@ua.es (M.A.C.) \\ 2 Departamento de Ingeniería Civil, Urbanismo y Aeroespacial, Escuela de Arquitectura, Ingeniería y \\ Diseño, Universidad Europea, c/ Tajo s/n, 28670, Villaviciosa de Odón, Madrid, Spain; \\ mariadolores.esteban@universidadeuropea.es (M.D.E.) \\ 3 Engineeria, 7 Ridgmount Street, London, WC1E 7AE, U.K.; markmboro@gmail.com (M.W.) \\ * Correspondence: jm.ortega@ua.es; Tel.: +34-96-5903-400 (ext. 1167)
}

\begin{abstract}
The use of additions as clinker replacement has become very popular, due to the advantages that they provide, especially regarding the improvement of cement industry sustainability. The microstructure of cement-based materials has a direct influence on their service properties. In this research, mortars with different contents of silica fume (up to 10\%) have been studied. These mortars were exposed to aggressive media with presence of sodium and magnesium sulphate along 90 days. On one hand, the evolution of their pore structure was characterised using different results provided by mercury intrusion porosimetry technique, such as intrusion-extrusion curves and logarithm of differential intrusion volume versus pore size curves. On the other hand, the compressive strength and the steady-state ionic diffusion coefficient obtained from resistivity of the samples, which was measured using impedance spectroscopy, were also studied. In general, silica fume mortars showed good performance, although the greatest deterioration of these mortars was observed in a mixed magnesium and sodium sulphate solution.
\end{abstract}

Keywords: silica fume; sulphate attack; sustainability; mercury intrusion porosimetry; ionic diffusion coefficient; mechanical strength.

\section{Introduction}

Nowadays, the use of additions in the cement production as clinker replacement has become very popular [1-6], because they provide several environmental benefits, such as the reduction of $\mathrm{CO}_{2}$ emissions produced along the cement manufacture. Furthermore, most of these additions are residues which come from other industrial sectors, therefore their reuse also constitutes a benefit by itself.

One of the most used active additions is silica fume [7-10]. On one hand, it has been established by various authors that silica fume addition results in an improvement in durability related characteristics such as permeability [11-13], electrical resistivity [14,15] and chloride diffusivity [1618]. These parameters are of fundamental importance as they affect the corrosion of reinforcing steel, which many authors consider to be the most severe pathology affecting reinforced concrete structures [19].

On the other hand, sulphate attack is another pathology which could produce deleterious effect in cement-based materials and structures. The classic harmful effects of this attack (ettringite and gypsum formation) are associated with the sulphate anion. It has been suggested that among the most typical associated cations, calcium and sodium are innocuous, while magnesium is aggressive 
[19]. The chemical reactions produced by the sodium sulphate attack are shown in equations 1 and 2 . The reaction of equation 2 produces the formation of expansive ettringite crystals.

$$
\begin{gathered}
\mathrm{Ca}(\mathrm{OH})_{2}+\mathrm{Na}_{2} \mathrm{SO}_{4}+2 \mathrm{H}_{2} \mathrm{O} \rightarrow \mathrm{CaSO}_{4} \cdot 2 \mathrm{H}_{2} \mathrm{O}+2 \mathrm{NaOH} \\
3 \mathrm{CaO} \cdot \mathrm{Al}_{2} \mathrm{O}_{3}+3 \mathrm{CaSO}_{4} \cdot 2 \mathrm{H}_{2} \mathrm{O}+26 \mathrm{H}_{2} \mathrm{O} \rightarrow 3 \mathrm{CaO} \cdot \mathrm{Al}_{2} \mathrm{O}_{3} \cdot 3 \mathrm{CaSO}_{4} \cdot 32 \mathrm{H}_{2} \mathrm{O}
\end{gathered}
$$

The chemical reactions produced by the magnesium ion are shown in equations 3 and 4 . The reaction shown in equation 3 results in the formation of magnesium hydroxide, or brucite, and is not greatly deleterious as calcium hydroxide does not contribute much to the strength of the hardened cement paste. The reaction shown in equation 4 is referred to as decalcification henceforth, and results in a severe loss of compressive strength due to the conversion of conglomerate calcium silica hydrate (C-S-H) gels into non-conglomerate magnesium silica hydrates(M-S-H) [20-22].

$$
\begin{gathered}
\mathrm{Mg}^{2+}+\mathrm{Ca}(\mathrm{OH})_{2} \rightarrow \mathrm{Mg}(\mathrm{OH})_{2}+\mathrm{Ca}^{2+} \\
\mathrm{Mg}^{2+}+\mathrm{C}-\mathrm{S}-\mathrm{H} \rightarrow \mathrm{M}-\mathrm{S}-\mathrm{H}+\mathrm{Ca}^{2+}
\end{gathered}
$$

In relation to silica fume addition, it has been well documented that this addition increases resistance to sulphate ion attack, due to the consumption of portlandite during the pozzolanic reaction [23,24]. Then, as less portlandite is available to react with sulphate ions, fewer expansive reaction products (gypsum and ettringite) are formed. Other authors have observed experimentally that these results entailed a substantial reduction in expansion and a lower loss of compressive strength in silica fume blended cements [23-25].

However, when the associated cation is magnesium, the addition of silica fume has been shown to result in greater deterioration [24,26,27]. It has been agreed that this is a result of the lower availability of portlandite, which reacts with magnesium to form a double layer of brucite and gypsum, which was experimentally observed by Lee et al. (2005) [24]. This forms a barrier to the ingress of sulphate and magnesium ions, and additionally means that fewer magnesium ions are available to react with the hardened cement paste's calcium silica hydrate gels (so called "decalcification") [24]. The latter reaction is far more damaging, as the resulting magnesium silica hydrate gels are non-conglomerate. Decalcification therefore results in the disintegration of the hardened cement paste and an important loss of compressive strength.

Whereas the effects of reactions involving the sulphate anion have been extensively studied, the microstructural changes produced in the pore network have received less attention, especially in terms of porosity and pore size distribution. Furthermore, the current literature available does not consider the effects of microstructure deterioration resulting from exposure to either sulphate or magnesium ions on durability characteristics and mechanical properties, although some authors have noted small decreases in porosity during the initial phases of sulphate ion attack [28].

Then, the main purpose of the present paper is to investigate the effect of exposure to magnesium and sodium sulphate solutions on the microstructure and properties of mortars with different contents of silica fume, compared to mortars containing ordinary Portland cement only. Moreover, this study complements two previous authors' works $[29,30]$ in which several types of sustainable mortars and grouts with silica fume exposed to sulphate attack were studied.

\section{Materials and Methods}

\subsection{Sample Preparation and Curing}

Three types of mortars were analysed. For all of them the cement used was a high early strength type, belonging to European cement class CEM I 42.5 R [31]. The first type of mortar had no addition of silica fume (referred to as $0 \%$ silica fume mortar hereafter), and it was used as a pattern for performance. Apart from that, two mortars in which $5 \%$ and $10 \%$ of cement was replaced with silica 
fume were also studied (designated as $5 \%$ silica fume and 10\% silica fume mortars respectively from now on). The silica fume used was not densified, with $90.78 \%$ of its particles under $1 \mu \mathrm{m}$ and an average particle diameter of $0.67 \mu \mathrm{m}$. The chemical composition of the materials and calculated clinker compounds of the cement are shown in Table 1 . The fine aggregate to binder ratio was 3:1 and the water to binder ratio was 0.5, as prescribed by standard UNE-EN 196-1 [32]. Cylindrical $(10 \mathrm{~cm}$ diameter and $15 \mathrm{~cm}$ height) and prismatic $(4 \mathrm{~cm} \times 4 \mathrm{~cm} \times 16 \mathrm{~cm})$ specimens were made. The samples were cured for 7 days in a temperature and humidity controlled chamber at $20^{\circ} \mathrm{C}$ and $95 \%$ relative humidity (RH). Following this period they were de-moulded, cut to shape as required, and introduced into the corresponding sulphate solution. In particular, the cylindrical specimens were cut in $2 \mathrm{~cm}$ thick slices, and the prismatic samples were divided in three identical elements whose dimensions were $4 \mathrm{~cm} \times 4 \mathrm{~cm} \times 5.3 \mathrm{~cm}$. The samples were tested at different times, until 90 days of contact with the sulphate solutions.

Table 1. Chemical composition of the cement and silica fume.

\begin{tabular}{ccc}
\hline Compound & CEM I 42.5R (\%) & Silica Fume (\%) \\
\hline $\mathrm{CaO}$ & 64.5 & 0.4 \\
$\mathrm{SiO}_{2}$ & 20.0 & 94.1 \\
$\mathrm{Al}_{2} \mathrm{O}_{3}$ & 5.7 & 0.3 \\
$\mathrm{Fe}_{2} \mathrm{O}_{3}$ & 2.5 & 0.1 \\
$\mathrm{SO}_{3}$ & 3.2 & 0.1 \\
$\mathrm{MgO}$ & 0.9 & 0.3 \\
$\mathrm{Na} 2$ & 0.1 & 0.6 \\
$\mathrm{~K}_{2} \mathrm{O}$ & 1.0 & 0.6 \\
\hline
\end{tabular}

\subsection{Sulphate Solutions}

The specimens were exposed to three sulphate solutions. The sulphate solutions used consisted of combinations of reagent grade magnesium sulphate $\left(\mathrm{MgSO}_{4}\right)$ and sodium sulphate $\left(\mathrm{Na}_{2} \mathrm{SO}_{4}\right)$ dissolved in distilled water, and changed once after 45 days. The content in sulphate and magnesium ions present in each solution is shown in Table 2. Each solution is denominated by the percentage by weight of dissolved sulphates. The volume of solutions was approximately 4 times the volume of the samples, as is suggested by the ASTM C 1012-04 standard [33]. Finally, the relatively high concentration of sulphate (15\%) was chosen for speeding up the harmful effects produced by this aggressive ion, in order to note them at short exposure times.

Table 2. Content in aggressive ions and ratio of magnesium to sulphate ions in the sulphate solutions used.

\begin{tabular}{|c|c|c|c|c|c|c|}
\hline Solution Name & $\begin{array}{l}\mathrm{Mg}^{2+} \\
(\mathrm{g} / \mathrm{l})\end{array}$ & $\begin{array}{l}\mathrm{SO}_{4}{ }^{--} \\
(\mathrm{g} / \mathrm{l})\end{array}$ & $\begin{array}{l}\text { Mass Ratio } \\
\mathrm{Mg}^{2+} / \mathrm{SO}_{4}{ }^{2-}\end{array}$ & $\begin{array}{c}\mathrm{Mg}^{2+} \\
(\mathrm{mol} / \mathrm{l})\end{array}$ & $\begin{array}{l}\mathrm{SO}_{4}{ }^{2-} \\
(\mathrm{mol} / \mathrm{l})\end{array}$ & $\begin{array}{l}\text { Molar ratio } \\
\mathrm{Mg}^{2+} / \mathrm{SO}_{4}{ }^{2-}\end{array}$ \\
\hline $15 \% \mathrm{Na}_{2} \mathrm{SO}_{4}$ & 0 & 101.442 & 0 & 0 & 1.056 & 0 \\
\hline $\begin{array}{c}7.5 \% \mathrm{MgSO}_{4}+ \\
7.5 \% \mathrm{Na}_{2} \mathrm{SO}_{4}\end{array}$ & 15.145 & 110.576 & 0.136 & 0.621 & 1.151 & 0.539 \\
\hline $15 \% \mathrm{MgSO}_{4}$ & 30.290 & 119.710 & 0.253 & 1.246 & 1.246 & 1.000 \\
\hline
\end{tabular}

\subsection{Mercury Intrusion Porosimetry}

A porosimeter model AUTOPORE IV 9500 of Micromeritics (Norcross, GA, USA) was used. The apparatus allowed the determination of the volume of pores with an accessible diameter of $5 \mathrm{~nm}$ to $900 \mu \mathrm{m}$. The samples were taken from slices with $2 \mathrm{~cm}$ thickness, and they were dried in an oven at $50^{\circ} \mathrm{C}$ along one week before testing. Two measurements were performed for each material, solution and testing age. The intrusion-extrusion curves, the curves logarithm of differential intrusion volume 
versus pore size and the median pore diameter were analysed. The tests were made at 21 and 90 days of exposure to the different studied solutions.

\subsection{Determination of Steady-State Ionic Diffusion Coefficient from Resistivity of Sample Obtained Using Impedance Spectroscopy}

The electrical resistivity measurement of a cement-based material is an indirect method to assess their pore connectivity and determine the ionic steady-state diffusion coefficient Ds [34]. Here, the electrical resistivity was calculated from the electrical resistance of the specimens immersed in the sulphate solutions, using the non-destructive impedance spectroscopy technique [35-37]. This technique has successfully been used in several previous authors' researches for characterising the pore network of cement-based materials with silica fume [29,30] and other active additions [38,39].

In the current work, the impedance measurements were carried out in $2 \mathrm{~cm}$ thick slices using an impedance analyzer Agilent 4294A (Agilent Technologies, Kobe, Japan), capable of capacitance measurements in the $10^{-14}-0.1 \mathrm{~F}$ range, with a maximum resolution of $10^{-15} \mathrm{~F}$. Circular copper electrodes with a flexible graphite contact surface and a diameter of $8 \mathrm{~cm}$ were used, and measurements were taken over a frequency range of $100 \mathrm{~Hz}$ to $100 \mathrm{MHz}$. The electrodes were placed in direct contact with the samples during measurement. The obtained spectra were fitted to the equivalent circuit proposed by Cabeza et al. [36] (see Figure 1) using a simplex algorithm, described elsewhere [40]. One of the circuital elements is the resistance $R_{1}$ (see Figure 1), which is associated with pores that cross the sample. This resistance $R_{1}$ is equivalent to the electrical resistance of the sample [41,42].

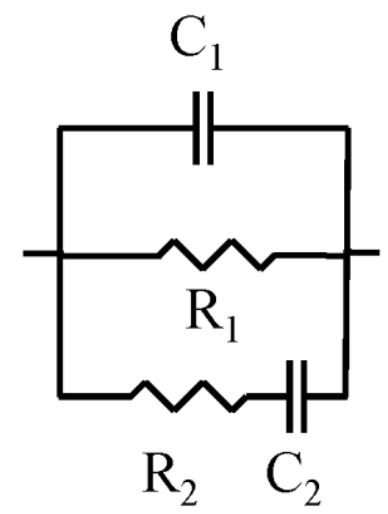

Figure 1. Equivalent circuit used for the fitting of the impedance spectra obtained using the contacting method, in which the resistance $R_{1}$ is associated with pores that cross the sample.

The steady-state ionic diffusion coefficient $\left(D_{s}\right)$ was calculated according to the expression proposed by Andrade et al. [34], shown in equation 5, in which the coefficient $D_{s}$ is expressed in $\mathrm{m}^{2} / \mathrm{s}$, and the electrical resistivity $\mathrm{Q}$ in $\Omega \cdot \mathrm{m}$.

$$
\mathrm{D}_{\mathrm{s}}=\frac{2 \times 10^{-10}}{\rho}
$$

For each mortar type and solution four different samples were tested. The variation in steadystate ionic coefficient was followed up to 90 days of exposure to the sulphate solutions.

\subsection{Compressive Strength}

The compressive strength was determined according to the Spanish standard UNE-EN 196-1 [32], in prisms of dimensions $4 \mathrm{~cm} \times 4 \mathrm{~cm} \times 5.3 \mathrm{~cm}$. Three different samples were tested for each mortar type and solution. This parameter was obtained at 21 and 90 days of exposure to the sulphate solutions. 


\section{Results and Discussion}

\subsection{Mercury Intrusion Porosimetry}

The intrusion-extrusion curves for samples exposed to the $15 \% \mathrm{Na}_{2} \mathrm{SO}_{4}$ solution are depicted in Figure 2 and their median pore diameters are noted in Table 3. It may be noted that in the $0 \%$ silica fume samples, the total intrusion volume increased very slightly with exposure period, increasing by less than 1\% from 21 days to 90 days exposure. For the median pore diameter an increase was observed. Some variations were also observed in the values recorded in the 5\% and $10 \%$ silica fume samples. For $5 \%$ silica fume specimens, a slight increase in the total intrusion volume has been noted, as well as for the median pore diameter. In the case of $10 \%$ silica fume samples, the total intrusion volume slightly decreased from 21 to 90 days, and the median pore diameter rose in this period. The lowest increase of this parameter between 21 and 90 days has been observed for $10 \%$ silica fume specimens, followed by $5 \%$ silica fume ones. On the other hand, for the $15 \% \mathrm{Na}_{2} \mathrm{SO}_{4}$ solution the highest increase of the median pore diameter along the studied period corresponded to $0 \%$ silica fume samples.

The intrusion-extrusion curves for samples exposed to the mixed solution are shown in Figure 3 and their median pore diameters can be observed in Table 3. The total intrusion volume was relatively unaffected by exposure to this $7.5 \% \mathrm{MgSO}_{4}+7.5 \% \mathrm{Na}_{2} \mathrm{SO}_{4}$ solution in the $0 \%$ and $10 \%$ silica fume samples, and that a reduction was observed with exposure period in the $5 \%$ silica fume samples. A reduction of the median pore diameter was observed for $5 \%$ silica fume specimens, and this parameter increased for $0 \%$ and $10 \%$ silica fume ones, being this rise very important for the last type of samples.
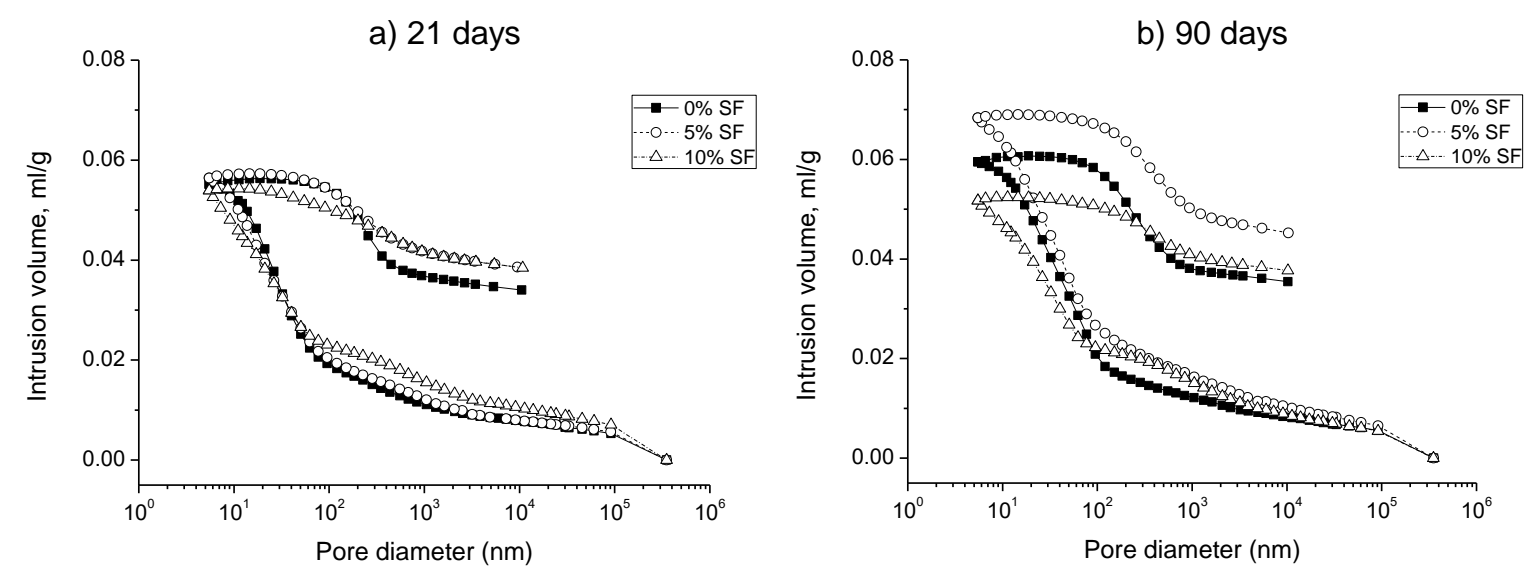

Figure 2. (a) Intrusion-extrusion curves at 21 days of exposure to the $15 \% \mathrm{Na}_{2} \mathrm{SO}_{4}$ solution for mortars prepared using ordinary Portland cement without addition ( $0 \% \mathrm{SF})$, and for those with a content of $5 \%(5 \%$ $\mathrm{SF})$ and $10 \%(10 \% \mathrm{SF})$ of silica fume; (b) Intrusion-extrusion curves at 90 days of exposure to the $15 \% \mathrm{Na}_{2} \mathrm{SO}_{4}$ solution noted for the studied mortars.

Regarding the samples exposed to the $15 \% \mathrm{MgSO}_{4}$ solution, their intrusion-extrusion curves can be observed in Figure 4, while their median pore diameters are included in Table 3. Scarce differences were observed between the different types of studied samples in relation the total intrusion volume. However, the median pore diameter rose with time for all the studied samples, and this increase is higher as greater is the content of silica fume, being especially noticeable for specimens with a $10 \%$ content of this addition. 
a) 21 days

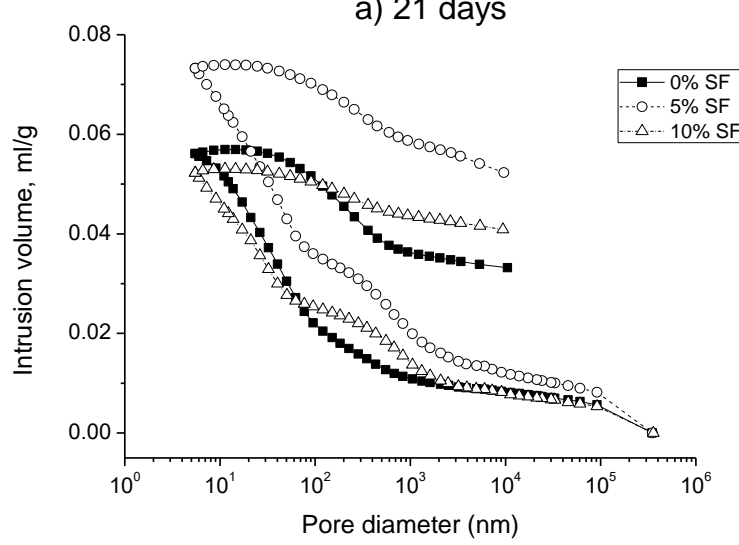

b) 90 days

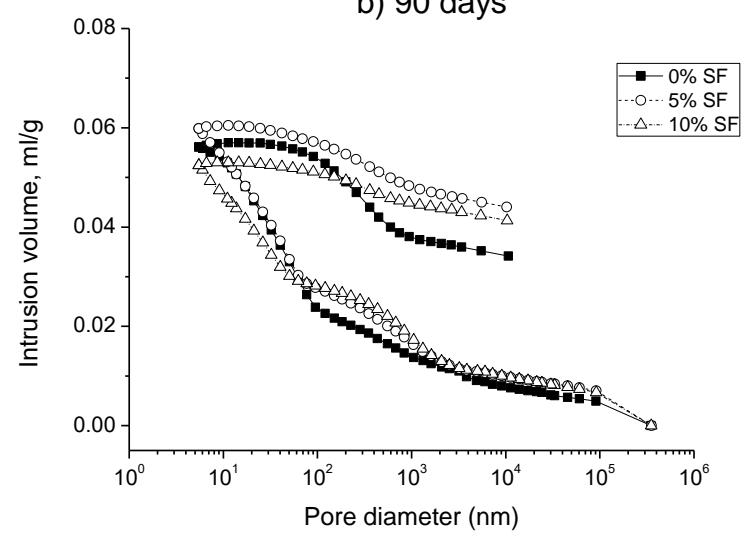

Figure 3. (a) Intrusion-extrusion curves at 21 days of exposure to the mixed solution $\left(7.5 \% \mathrm{Na}_{2} \mathrm{SO}_{4}+7.5 \%\right.$ $\mathrm{MgSO}_{4}$ ) for the analysed mortars; (b) Intrusion-extrusion curves at 90 days of exposure to the mixed solution $\left(7.5 \% \mathrm{Na}_{2} \mathrm{SO}_{4}+7.5 \% \mathrm{MgSO}_{4}\right)$ obtained for the studied mortars.

Table 3. Median pore diameter ( $\mathrm{nm}$ ) measured for the studied mortars.

\begin{tabular}{cccccccccc}
\hline \multirow{2}{*}{$\begin{array}{c}\text { Mortar } \\
\text { type }\end{array}$} & \multicolumn{2}{c}{$\mathbf{1 5 \%} \mathbf{~ N a}_{2} \mathrm{SO}_{4}$ solution } & \multicolumn{3}{c}{ Mixed solution } & \multicolumn{2}{c}{$\mathbf{1 5 \%} \mathbf{~ M g S O}_{4}$ solution } \\
\cline { 2 - 9 } & $\mathbf{2 1}$ days & $\mathbf{9 0}$ days & Variation & 21 days & $\mathbf{9 0}$ days & Variation & $\mathbf{2 1}$ days & $\mathbf{9 0}$ days & Variation \\
\hline $0 \% \mathrm{SF}$ & 43.3 & 58.8 & $35.8 \%$ & 58.8 & 68.8 & $17.0 \%$ & 60.8 & 67.5 & $11.0 \%$ \\
$5 \% \mathrm{SF}$ & 44.4 & 55.6 & $25.2 \%$ & 86.3 & 64.6 & $-25.1 \%$ & 79.7 & 97.5 & $22.3 \%$ \\
$10 \% \mathrm{SF}$ & 48.8 & 54.3 & $11.3 \%$ & 72.3 & 216.1 & $198.9 \%$ & 79.6 & 289.2 & $263.3 \%$ \\
\hline
\end{tabular}
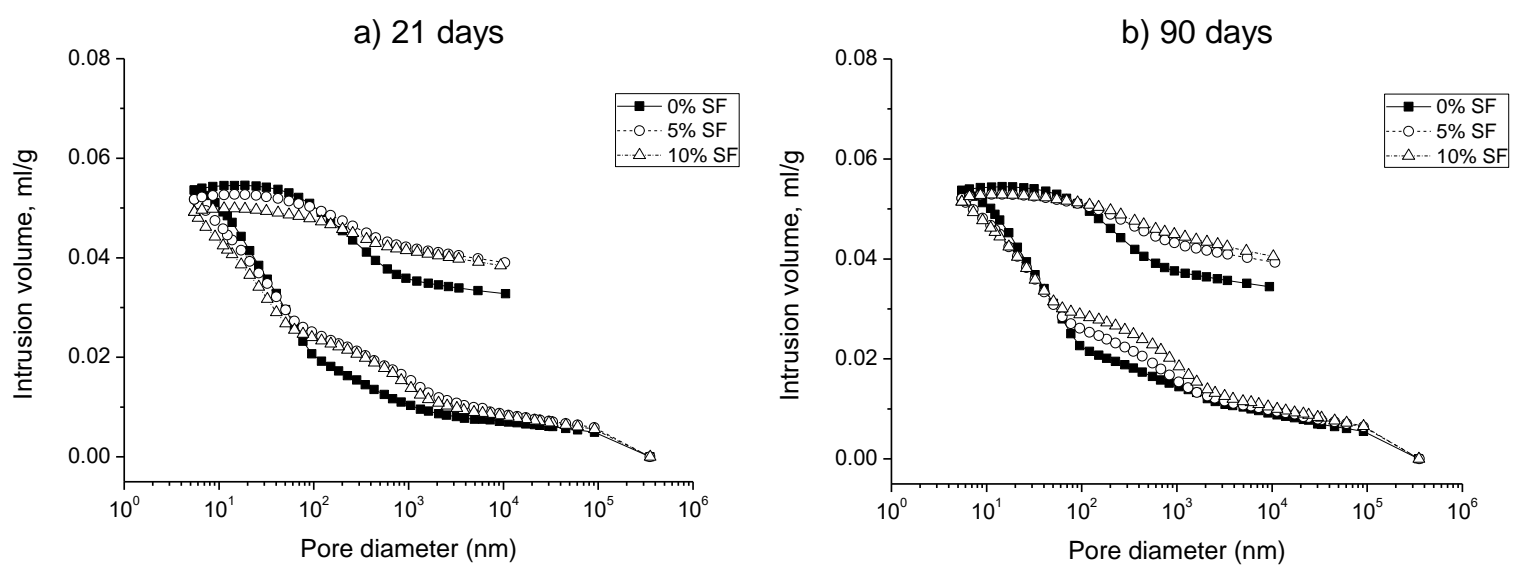

Figure 4. (a) Intrusion-extrusion curves at 21 days of exposure to the $15 \% \mathrm{MgSO}_{4}$ solution for the studied mortars; (b) Intrusion-extrusion curves at 90 days of exposure to the $15 \% \mathrm{MgSO}_{4}$ solution noted for the studied mortars.

The curves logarithm of differential intrusion volume versus pore size obtained for the samples exposed to the $15 \% \mathrm{Na}_{2} \mathrm{SO}_{4}$ solution at 21 and 90 days are shown in Figure 5 . In the $0 \%$ silica fume samples, the principal effect appears to be on the pore family whose centre is at around $2 \cdot 10^{1} \mathrm{~nm}$. At 90 days, a widening of this pore family may be observed and now the main peak of this family is around $10^{2} \mathrm{~nm}$. This would indicate a loss of pore refinement for $0 \%$ silica fume samples which could be due to the development of sulphate attack [29,30]. At 21 days the samples containing silica fume both showed two peaks in the range $10^{1}-10^{2} \mathrm{~nm}$, which merged in one peak at 90 days, whose diameter was lower than that noted for $0 \%$ silica fume specimens. This result is consistent with the established idea that samples containing silica fume show a more refined pore structure, and in 
agreement with results presented by other authors $[13,16,43]$. Furthermore, in view of the differential intrusion volume, the samples containing $10 \%$ silica fume appear not to have been greatly affected between 21 and 90 days exposure, while the $5 \%$ silica fume sample showed a greater volume of pores present in the abovementioned pore family.

In Figure 6 it can be observed the curves logarithm of differential intrusion volume versus pore size obtained for the samples exposed to the mixed solution. From this figure, the principal pore family (between $10^{1}$ and $10^{2} \mathrm{~nm}$ ) for the $0 \%$ silica fume samples was relatively unaffected, although the main peak in the previously mentioned range moved to higher diameters from 21 to 90 days, and a small peak appeared at approximately $3 \cdot 10^{3} \mathrm{~nm}$. For samples containing silica fume, apart from the family in the range $10^{1}$ and $10^{2} \mathrm{~nm}$, a prominent pore family centred at around $10^{3} \mathrm{~nm}$ was observed, which was not registered in the samples exposed to the $15 \% \mathrm{Na}_{2} \mathrm{SO}_{4}$ solution. This would mean that the microstructure of silica fume mortars would be more affected by the exposure to the mixed solution than by the sodium sulphate one, as suggested the loss of pore refinement indicated by this new pores family with higher diameter. Slight changes has been noted in the pore families observed for silica fume specimens from 21 days to 90 days, although it may be observed that the $10 \%$ silica fume samples' principal pore family showed a small decrease.

\section{a) 21 days}

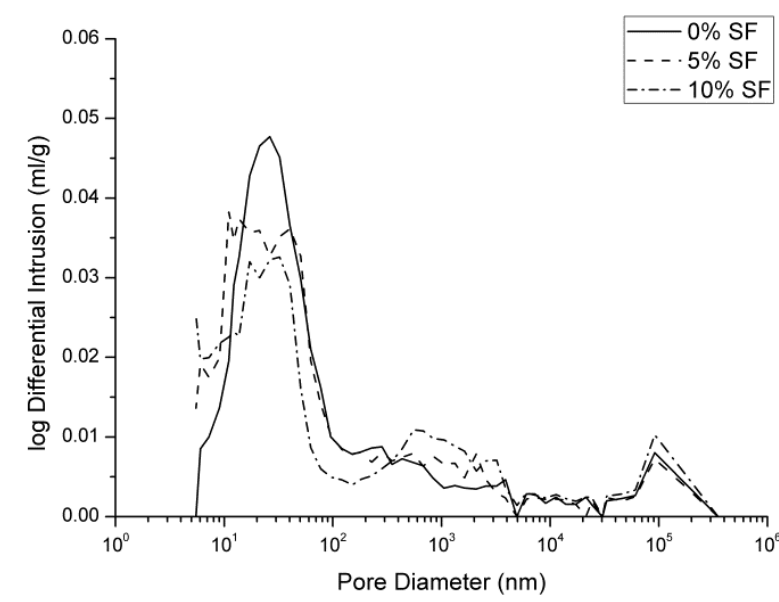

b) 90 days

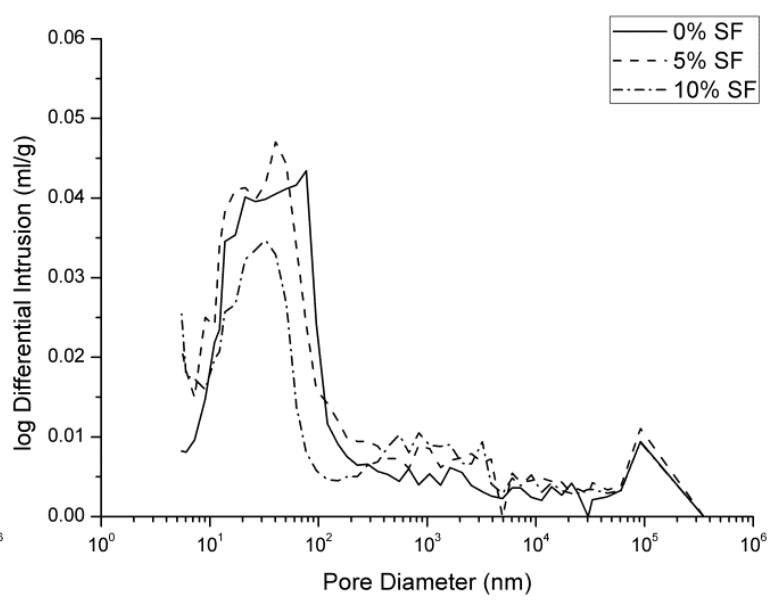

Figure 5. (a) Curves logarithm of differential intrusion volume versus pore size obtained at 21 days of exposure to the $15 \% \mathrm{Na}_{2} \mathrm{SO}_{4}$ solution; (b) Curves logarithm of differential intrusion volume versus pore size obtained at 90 days of exposure to the $15 \% \mathrm{Na}_{2} \mathrm{SO}_{4}$ solution.

In relation to the curves logarithm of differential intrusion volume versus pore size noted for the samples exposed to the $15 \% \mathrm{MgSO}_{4}$ solution (see Figure 7), they showed similarities to those observed for the mixed solution. For $0 \%$ silica fume samples, the main pores family was again in the interval $10^{1}-10^{2} \mathrm{~nm}$, although at 90 days a noticeable peak appeared approximately at $2 \cdot 10^{3} \mathrm{~nm}$, as happened for the mixed solution. For $5 \%$ and $10 \%$ silica fume specimens the same prominent pore family at around $10^{3} \mathrm{~nm}$ was present and it slightly increased in size between 21 and 90 days exposure. This appears to suggest that the formation of this pore family resulted from the deterioration processes associated with the magnesium ion [24,27], as it was not observed in the samples exposed to the $15 \%$ $\mathrm{Na}_{2} \mathrm{SO}_{4}$ solution. Regarding the main peak of the range $10^{1}-10^{2} \mathrm{~nm}$ for the silica fume mortars, it slightly displaced to greater pore sizes between 21 and 90 days, which would show the deleterious effects of the $\mathrm{MgSO}_{4}$ solution in their microstructure [26,27]. 
a) 21 days

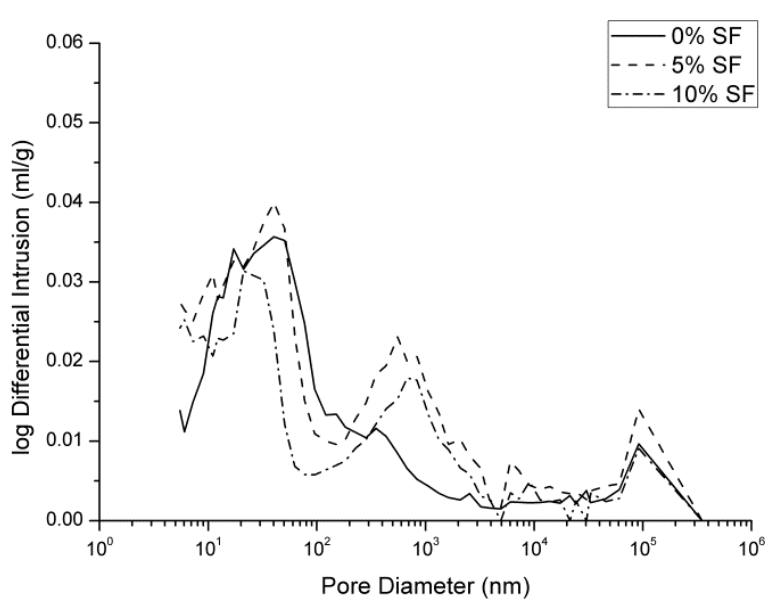

b) 90 days

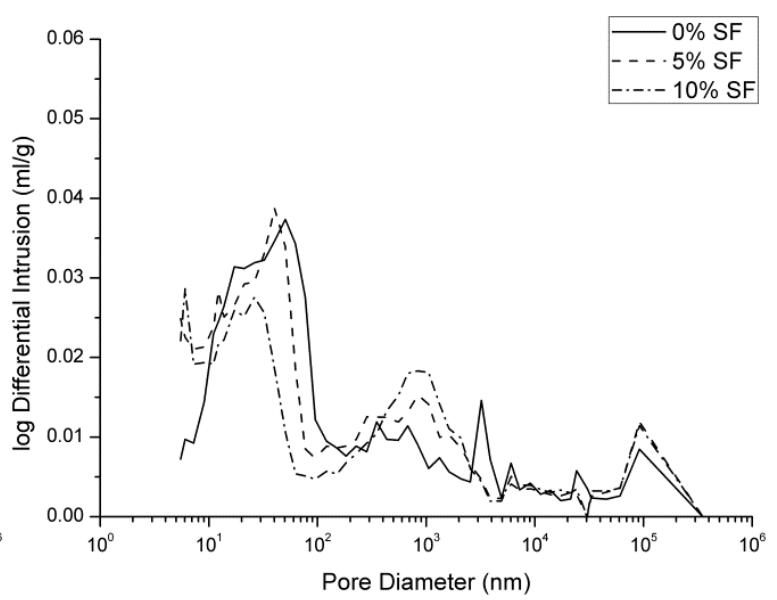

Figure 6. (a) Curves logarithm of differential intrusion volume versus pore size showed by the studied mortars at 21 days of exposure to the mixed solution; (b) Curves logarithm of differential intrusion volume versus pore size showed by the studied mortars at 90 days of exposure to the mixed solution.

a) 21 days

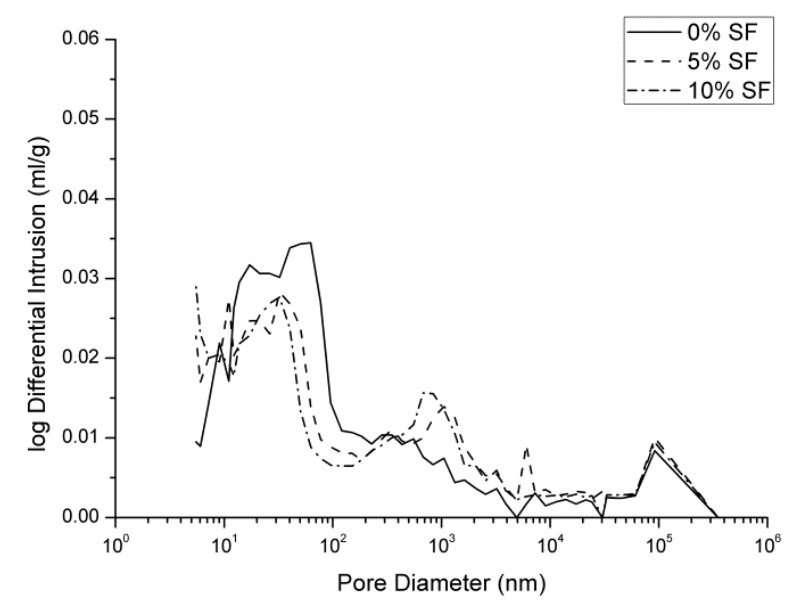

b) 90 days

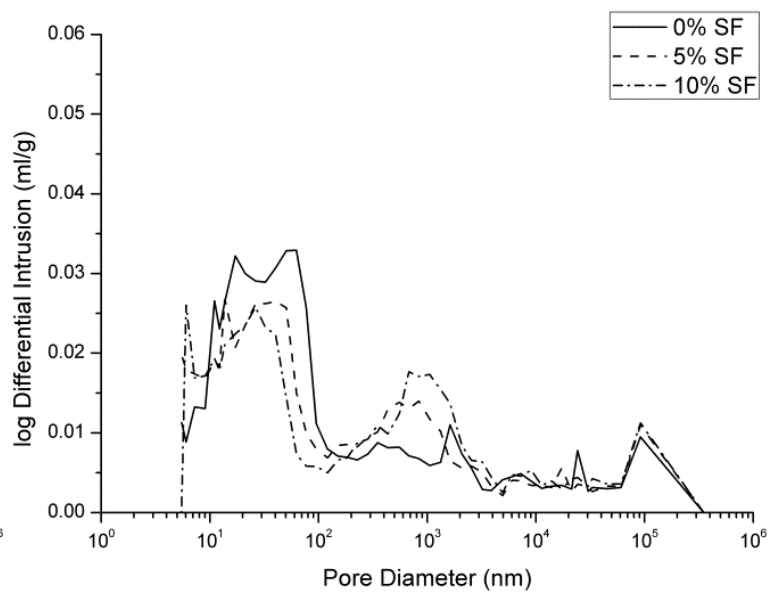

Figure 7. (a) Curves logarithm of differential intrusion volume versus pore size obtained at 21 days of exposure to the $15 \% \mathrm{MgSO}_{4}$ solution; (b) Curves logarithm of differential intrusion volume versus pore size obtained at 90 days of exposure to the $15 \% \mathrm{MgSO}_{4}$ solution.

\subsection{Steady State Ionic Diffusion Coefficient}

The changes with time in the steady state ionic diffusion coefficient $\left(\mathrm{D}_{s}\right)$ measured in samples exposed to the $15 \% \mathrm{Na}_{2} \mathrm{SO}_{4}$ solution can be observed in Figure 8. This figure shows firstly that, in agreement with the published literature discussed previously [16-18], the steady state ionic diffusion coefficient $\left(\mathrm{D}_{\mathrm{s}}\right.$ ) decreased with silica fume content. Additionally, exposure to the $15 \% \mathrm{Na}_{2} \mathrm{SO}_{4}$ solution appears not to have produced any increase in $D_{s}$, which suggests that the sulphate resistance of the samples containing silica fume was high. In fact, the silica fume samples showed a relatively constant reduction in $\mathrm{D}_{\mathrm{s}}$, which may have been linked to the continued pozzolanic reaction of the silica fume present. No increase in $\mathrm{D}_{s}$ was observed in the $0 \%$ silica fume samples, implying that sulphate attack did not affect this parameter, at least during the relative short time period studied. 


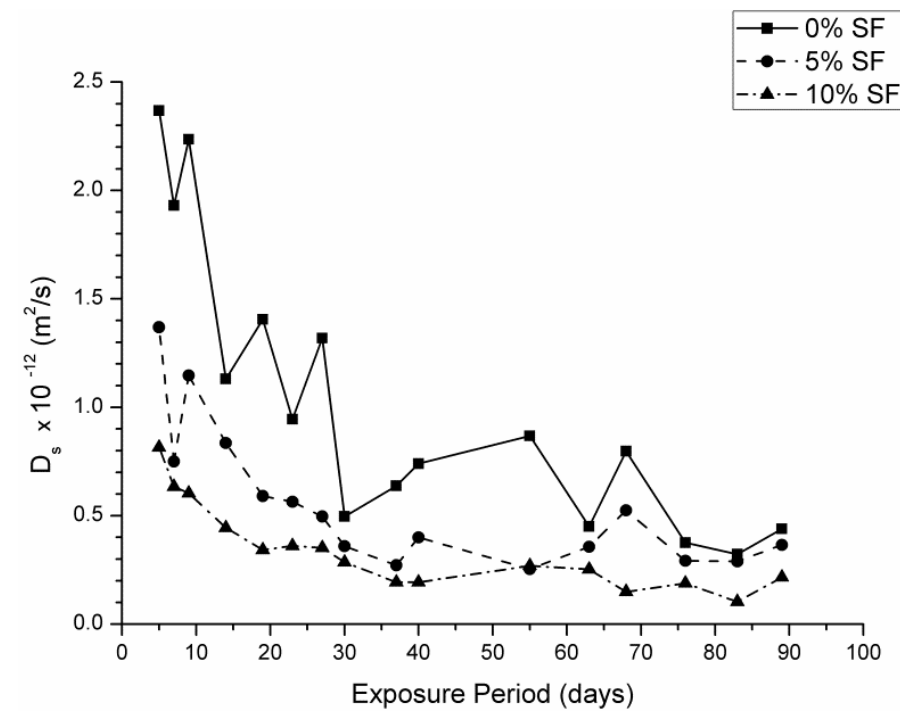

Figure 8. Variation in the steady state ionic diffusion coefficient $\left(\mathrm{D}_{\mathrm{s}}\right)$ measured in samples exposed to the $15 \% \mathrm{Na}_{2} \mathrm{SO}_{4}$ solution.

Regarding the $7.5 \% \mathrm{MgSO}_{4}+7.5 \% \mathrm{Na}_{2} \mathrm{SO}_{4}$ solution, it may be observed from Figure 9 that the samples containing $0 \%$ silica fume show a similar reduction in $\mathrm{D}_{\text {s }}$ to that observed in the $15 \% \mathrm{Na}_{2} \mathrm{SO}_{4}$ solution. This may be as a result of the formation of a double layer of brucite and gypsum, as discussed previously [24]. However, both the samples containing $5 \%$ and $10 \%$ silica fume showed an increase in $\mathrm{D}_{\mathrm{s}}$ after an initial decrease (probably associated with the initial pozzolanic hydration of the silica fume). This suggests that exposure to the $7.5 \% \mathrm{MgSO}_{4}+7.5 \% \mathrm{Na}_{2} \mathrm{SO}_{4}$ solution resulted in deterioration in these samples, which could be very severe in the long-term. It may be noted, for instance, that in the $10 \%$ silica fume sample, $\mathrm{D}_{\text {s }}$ was greater by the end of the exposure period than the initial value recorded at a sample age of 11 days (4 days exposure).

This deterioration was likely as a result of decalcification reactions, as observed by other authors [20-22]. The conversion of C-S-H gels to non-conglomerate M-S-H gels within the pore network would plausibly have the effect of dissolving hardened cement paste, decreasing the tortuosity of the pore network and increasing the porosity. As such, it may be inferred that exposure to magnesium ions increases ionic diffusivity in samples containing silica fume. It is also significant that by the end of the test period, the values of $D_{s}$ measured in the samples containing silica fume were almost double those measured in the sample containing Portland cement only.

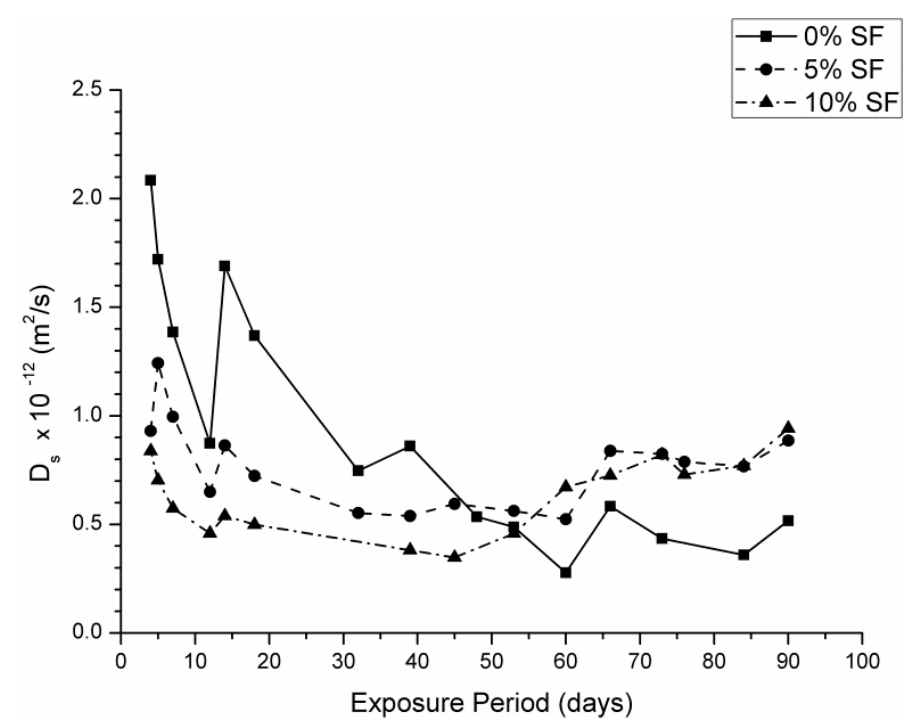

Figure 9. Variation in the steady state ionic diffusion coefficient $\left(D_{s}\right)$ measured in samples exposed to the mixed solution. 
However, the results of the steady state ionic diffusion coefficient $\left(D_{s}\right)$ measured in the samples exposed to the $15 \% \mathrm{MgSO}_{4}$ solution, presented in Figure 10, somewhat conflict with the idea that it is purely the action of the magnesium ion that causes an increase in $\mathrm{D}_{\mathrm{s}}$. Despite the fact that the samples shown in that figure were exposed to the $15 \% \mathrm{MgSO}_{4}$ solution with the highest concentration of

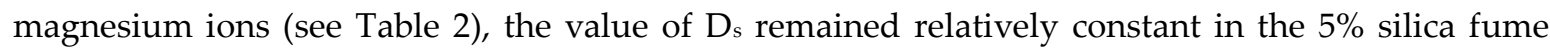
samples, and in the $10 \%$ silica fume samples it increased only slightly with exposure period compared to the lowest $\mathrm{D}_{s}$ value noted. This appears to suggest that changes in the ionic diffusivity in silica fume samples are not directly proportional to the concentration of magnesium ions present. It would hence appear that the deterioration mechanism is more complex than previously assumed.

The $0 \%$ silica fume samples exposed to the $15 \% \mathrm{MgSO}_{4}$ solution showed a relatively constant decrease in $\mathrm{D}_{\text {s. }}$ It may be noted that in all of the solutions, the values of $\mathrm{D}_{\mathrm{s}}$ were very similar by the end of the exposure period, despite some differences in the initial values. These results appear to suggest that in non-blended cements, sulphate attack does not result in significant changes in the steady state ionic diffusion coefficient. However, it should be noted that the solutions used were extremely concentrated and the test period was short (90 days), and as such further research is necessary to confirm this assertion.

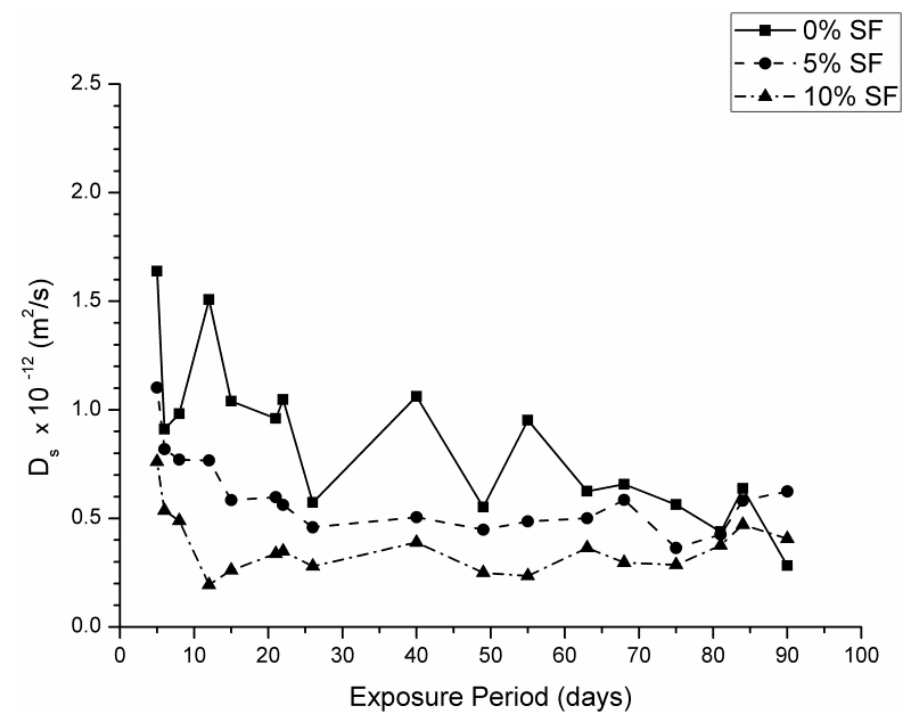

Figure 10. Variation in the steady state ionic diffusion coefficient $\left(\mathrm{D}_{\mathrm{s}}\right)$ measured in samples exposed to the $15 \% \mathrm{MgSO}_{4}$ solution.

\subsection{Compressive Strength}

The compression strength results and its variation in percentage between 21 and 90 exposure days are shown in Table 4 for all the samples and solutions studied. In that table, it may be observed that exposure to the $\mathrm{Na}_{2} \mathrm{SO}_{4}$ solution did not result in any substantial reduction in compressive strength in the samples containing both $5 \%$ and $10 \%$ silica fume, even this parameter slightly increased for them, but a significant reduction of $34.4 \%$ was observed in the $0 \%$ silica fume samples. This correlates well with data available in current literature $[23,24,26,44]$, and is probably due to the silica fume samples having substantially less portlandite available for reaction with the sulphate ions present in solution, as discussed previously.

It may be inferred from the compressive strength results that exposure to the $7.5 \% \mathrm{MgSO}_{4}+7.5 \%$ $\mathrm{Na}_{2} \mathrm{SO}_{4}$ solution resulted in severe deterioration (likely due to decalcification [20-22]) in both of the samples containing silica fume. However, the samples without silica fume showed relatively little deterioration in terms of compressive strength. In addition, the results of this parameter suggests that in the samples containing $0 \%$ silica fume, exposed to the $15 \% \mathrm{MgSO}_{4}$ solution resulted in least deterioration of all samples. In fact, there was actually an increase in compressive strength. 
Despite the total concentration of magnesium ions being highest in the $15 \% \mathrm{MgSO}_{4}$ solution, the loss of compressive strength observed in the silica fume samples was not as severe as that which occurred in those exposed to the $7.5 \% \mathrm{MgSO}_{4}+7.5 \% \mathrm{Na}_{2} \mathrm{SO}_{4}$ solution (see Table 4). This suggests that the deterioration mechanism responsible for the reduction in compressive strength in the silica fume samples does not depend solely on the concentration of magnesium ions present. It also appears that the extent of deterioration in the samples containing silica fume was less than that observed by other authors using weaker $\mathrm{MgSO}_{4}$ solutions [16,27,45]. It is hence possible that the use of a more concentrated solution and a shorter test period does not produce the same results.

Table 4. Compressive strength (MPa) results obtained for the studied mortars.

\begin{tabular}{cccccccccc}
\hline \multirow{2}{*}{$\begin{array}{c}\text { Mortar } \\
\text { type }\end{array}$} & \multicolumn{2}{c}{$\mathbf{1 5 \%} \mathbf{N a}_{2} \mathrm{SO}_{4}$ solution } & \multicolumn{3}{c}{ Mixed solution } & \multicolumn{2}{c}{$\mathbf{1 5 \%} \mathbf{M g S O}_{4}$ solution } \\
\cline { 2 - 9 } & $\mathbf{2 1}$ days & $\mathbf{9 0}$ days & Variation & 21 days & $\mathbf{9 0}$ days & Variation & $\mathbf{2 1}$ days & $\mathbf{9 0}$ days & Variation \\
\hline $0 \% \mathrm{SF}$ & 32.3 & 21.2 & $-34.4 \%$ & 36.5 & 34.9 & $-4.4 \%$ & 36.5 & 40.8 & $11.8 \%$ \\
$5 \% \mathrm{SF}$ & 57.9 & 59.9 & $3.5 \%$ & 53.0 & 44.2 & $-16.6 \%$ & 46.2 & 47.4 & $2.6 \%$ \\
$10 \% \mathrm{SF}$ & 63.3 & 67.5 & $6.6 \%$ & 59.2 & 45.1 & $-23.8 \%$ & 56.0 & 53.1 & $-5.2 \%$ \\
\hline
\end{tabular}

\section{Conclusions}

The main conclusions that can be drawn from the previously discussed results can be summarized as follows:

- The pore structure of $0 \%$ silica fume samples exposed to sodium sulphate solution was less refined compared to $5 \%$ and $10 \%$ silica fume ones. This would indicate that the silica fume inclusion improves the resistance to sodium sulphate attack in mortars.

- The microstructure of silica fume mortars was more affected by the exposure to the mixed $7.5 \% \mathrm{MgSO}_{4}+7.5 \% \mathrm{Na}_{2} \mathrm{SO}_{4}$ solution than by the sodium sulphate one, as suggested the loss of pore refinement indicated by the appearance of a new pore family with higher diameter. A similar result has been noted for magnesium sulphate solution.

- The steady state ionic diffusion coefficient decreases with silica fume content, and appears not to be affected by exposure to sodium sulphate solutions.

- In silica fume samples exposed to magnesium sulphate solutions, a substantial increase in ionic diffusivity accompanies a loss in compressive strength, suggesting that dissolution type reactions take place in these samples pore network. This attack was more severe in the $7.5 \%$ $\mathrm{MgSO}_{4}+7.5 \% \mathrm{Na}_{2} \mathrm{SO}_{4}$ solution, which implies that magnesium content alone does not determine the severity of attack.

Acknowledgments: The research work included in the paper has been financially supported by the University of Alicante (Spain) through project GRE13-25. The authors also wish to thank Cementos Portland Valderrivas S.A. and Grupo Ferroatlántica, S.A. for providing the cement and silica fume (respectively) used in this study.

Author Contributions: José Marcos Ortega and Mark Williams wrote the paper. José Marcos Ortega, Mark Williams and Isidro Sánchez performed the experiments. María Dolores Esteban and Miguel Ángel Climent supervised the research work and revised the paper. All the authors contributed to conceive and design the experiments, and to analyse and discuss the results.

Conflicts of Interest: The authors declare no conflict of interest.

\section{References}

1. Demirboğa, R. Thermal conductivity and compressive strength of concrete incorporation with mineral admixtures. Build. Environ. 2007, 42 (7), 2467-2471 DOI: 10.1016/j.buildenv.2006.06.010.

2. Ganjian, E.; Pouya, H. S. The effect of Persian Gulf tidal zone exposure on durability of mixes containing silica fume and blast furnace slag. Constr. Build. Mater. 2009, 23 (2), $644-652$ DOI: 
10.1016/j.conbuildmat.2008.02.009.

3. Ponikiewski, T.; Gołaszewski, J. The effect of high-calcium fly ash on selected properties of self-compacting concrete. Arch. Civ. Mech. Eng. 2014, 14 (3), 455-465 DOI: 10.1016/j.acme.2013.10.014.

4. Ortega, J. M.; Sánchez, I.; Climent, M. A. Impedance spectroscopy study of the effect of environmental conditions in the microstructure development of OPC and slag cement mortars. Arch. Civ. Mech. Eng. 2015, 15 (2), 569-583 DOI: 10.1016/j.acme.2014.06.002.

5. Glinicki, M.; Jóźwiak-Niedźwiedzka, D.; Gibas, K.; Dąbrowski, M. Influence of Blended Cements with Calcareous Fly Ash on Chloride Ion Migration and Carbonation Resistance of Concrete for Durable Structures. Materials (Basel). 2016, 9 (1), 18 DOI: 10.3390/ma9010018.

6. Ortega, J.M.; Sánchez, I.; Climent, M.A. Influence of environmental conditions on durability of slag cement mortars. In: Zachar, J., Claisse, P., Naik, T.R., Ganjian, E. (Eds.), Proceedings of the 2nd International Conference on Sustainable Construction Materials and Technologies, pp. 277-287, Ancona, Italy, 28-30 June 2010 .

7. Nochaiya, T.; Wongkeo, W.; Chaipanich, A. Utilization of fly ash with silica fume and properties of Portland cement-fly ash-silica fume concrete. Fuel 2010, 89 (3), 768-774 DOI: 10.1016/j.fuel.2009.10.003.

8. Estokova, A.; Kovalcikova, M.; Luptakova, A.; Prascakova, M. Testing Silica Fume-Based Concrete Composites under Chemical and Microbiological Sulfate Attacks. Materials (Basel). 2016, 9 (5), 324 DOI: 10.3390/ma9050324.

9. Xu, W.; Lo, Y. T.; Wang, W.; Ouyang, D.; Wang, P.; Xing, F. Pozzolanic Reactivity of Silica Fume and Ground Rice Husk Ash as Reactive Silica in a Cementitious System: A Comparative Study. Materials . 2016.

10. Behfarnia, K.; Farshadfar, O. The effects of pozzolanic binders and polypropylene fibers on durability of SCC to magnesium sulfate attack. Constr. Build. Mater. 2013, 38, 64-71 DOI: 10.1016/j.conbuildmat.2012.08.035.

11. Chung, D. D. L. Improving cement-based materials by using silica fume. J. Mater. Sci. 2002, 37 (4), $673-682$ DOI: 10.1023/A:1013889725971.

12. ACI. Guide for the Use of Silica Fume in Concrete (ACI 234R-06). American Concrete Institute. 2006.

13. Hooton, R. D. PERMEABILITY AND PORE STRUCTURE OF CEMENT PASTES CONTAINING FLY ASH, SLAG, AND SILICA FUME. In ASTM Special Technical Publication; 1986; pp 128-143.

14. Wolsiefer, J. T. Silica fume concrete: a solution to steel reinforcement corrosion in concrete. In Utilization of Industrial By-Products for Construction Materials; Publ by ASCE, 1993; pp 15-29.

15. Dotto, J. M. R.; Abreu, A. G. d.; Dal Molin, D. C. C.; Müller, I. L. Influence of silica fume addition on concretes physical properties and on corrosion behaviour of reinforcement bars. Cem. Concr. Compos. 2004, 26 (1), 31-39 DOI: 10.1016/S0958-9465(02)00120-8.

16. Poon, C. S.; Kou, S. C.; Lam, L. Compressive strength, chloride diffusivity and pore structure of high performance metakaolin and silica fume concrete. Constr. Build. Mater. 2006, 20 (10), 858-865 DOI: 10.1016/j.conbuildmat.2005.07.001.

17. Gjorv, O. E. Effect of condensed silica fume on steel corrosion in concrete. ACI Mater. J. 1995, 92 (6), 591598.

18. Ramezanianpour, A. A.; Malhotra, V. M. Effect of curing on the compressive strength, resistance to chloride-ion penetration and porosity of concretes incorporating slag, fly ash or silica fume. 1995, 17 (2), 125-133 DOI: 10.1016/0958-9465(95)00005-W.

19. Neville, A. The confused world of sulfate attack on concrete. Cem. Concr. Res. 2004, 34 (8), 1275-1296 DOI: 10.1016/j.cemconres.2004.04.004. 
20. Al-Amoudi, O. S. B. Performance of 15 reinforced concrete mixtures in magnesium-sodium sulphate environments. Constr. Build. Mater. 1995, 9 (3), 149-158 DOI: 10.1016/0950-0618(95)00007-3.

21. Baghabra Al-Amoudi, O. S. Attack on plain and blended cements exposed to aggressive sulfate environments. Cem. Concr. Compos. 2002, 24 (3-4), 305-316 DOI: 10.1016/S0958-9465(01)00082-8.

22. Ganjian, E.; Pouya, H. S. Effect of magnesium and sulfate ions on durability of silica fume blended mixes exposed to the seawater tidal zone. Cem. Concr. Res. 2005, 35 (7), 1332-1343 DOI: 10.1016/j.cemconres.2004.09.028.

23. Al-Dulaijan, S. U.; Maslehuddin, M.; Al-Zahrani, M. M.; Sharif, A. M.; Shameem, M.; Ibrahim, M. Sulfate resistance of plain and blended cements exposed to varying concentrations of sodium sulfate. Cem. Concr. Compos. 2003, 25 (4-5), 429-437 DOI: 10.1016/S0958-9465(02)00083-5.

24. Lee, S. T.; Moon, H. Y.; Swamy, R. N. Sulfate attack and role of silica fume in resisting strength loss. Cem. Concr. Compos. 2005, 27 (1), 65-76 DOI: 10.1016/j.cemconcomp.2003.11.003.

25. Hooton, R. D. Influence of silica fume replacement of cement on physical properties and resistance to sulfate attack, freezing and thawing, and alkali-silica reactivity. ACI Mater. J. 1993, 90 (2), 143-151.

26. Cohen, M. D.; Bentur, A. Durability of Portland cement-Silica fume pastes in magnesium sulfate and sodium sulfate solutions. ACI Mater. J. 1988, 85 (3), 148-157.

27. Türker, F.; Aköz, F.; Koral, S.; Yüzer, N. Effects of magnesium sulfate concentration on the sulfate resistance of mortars with and without silica fume. Cem. Concr. Res. 1997, 27 (2), 205-214.

28. Santhanam, M.; Cohen, M. D.; Olek, J. Mechanism of sulfate attack: A fresh look. Part 1: Summary of experimental results. Cem. Concr. Res. 2002, 32 (6), 915-921 DOI: 10.1016/S0008-8846(02)00724-X.

29. Ortega, J. M.; Esteban, M. D.; Rodríguez, R. R.; Pastor, J. L.; Ibanco, F. J.; Sánchez, I.; Climent, M. A. Influence of Silica Fume Addition in the Long-Term Performance of Sustainable Cement Grouts for Micropiles Exposed to a Sulphate Aggressive Medium. Materials 2017, 10, 890, doi:10.3390/ma10080890.

30. Williams, M.; Ortega, J. M.; Sánchez, I.; Cabeza, M.; Climent, M. A. Non-Destructive Study of the Microstructural Effects of Sodium and Magnesium Sulphate Attack on Mortars Containing Silica Fume Using Impedance Spectroscopy. Appl. Sci.2017, 7, 648, doi:10.3390/app7070648.

31. Asociación Española de Normalización y Certificación (AENOR). UNE-EN 197-1:2011. Composición, Especificaciones y Criterios de Conformidad de Los Cementos Comunes; AENOR: Madrid, Spain, 2011; p. 30. (in Spanish)

32. Asociación Española de Normalización y Certificación (AENOR). UNE-EN 196-1:2005. Métodos de ensayo de cementos. Parte 1: Determinación de resistencias mecánicas. AENOR: Madrid, Spain, 2005; p. 36. (in Spanish)

33. ASTM. Standard Test Method for Length Change of Hydraulic-Cement Mortars Exposed to a Sulfate Solution ASTM C 1012-04; ASTM International: Wesk Conshohocken, PA, USA, 2004; p. 6.

34. Andrade, C.; Alonso, C.; Arteaga, A.; Tanner, P. Methodology based on the electrical resistivity for the calculation of reinforcement service life. In Proceedings of the 5th CANMET/ACO International Conference on Durability of Concrete, supplementary papers.; Malhotra, V. M., Ed.; American Concrete Institute: Barcelona, Spain, 2000; pp 899-915.

35. Sánchez, I.; Nóvoa, X. R.; de Vera, G.; Climent, M. A. Microstructural modifications in Portland cement concrete due to forced ionic migration tests. Study by impedance spectroscopy. Cem. Concr. Res. 2008, 38 (7), 1015-1025 DOI: 10.1016/j.cemconres.2008.03.012.

36. Cabeza, M.; Merino, P.; Miranda, A.; Nóvoa, X. R.; Sanchez, I. Impedance spectroscopy study of hardened Portland cement paste. Cem. Concr. Res. 2002, 32 (6), 881-891 DOI: 10.1016/S0008-8846(02)00720-2.

37. Ortega, J. M.; Sánchez, I.; Climent, M. A. Impedance spectroscopy study of the effect of environmental 
conditions on the microstructure development of sustainable fly ash cement mortars. Materials. 2017, 10 (10) DOI: 10.3390/ma10101130.

38. Pastor, J. L.; Ortega, J. M.; Flor, M.; López, M. P.; Sánchez, I.; Climent, M. A. Microstructure and durability of fly ash cement grouts for micropiles. Constr. Build. Mater. 2016, 117, 47-57 DOI: 10.1016/j.conbuildmat.2016.04.154.

39. Ortega, J. M.; Esteban, M. D.; Rodríguez, R. R.; Pastor, J. L.; Ibanco, F. J.; Sánchez, I.; Climent, M. A. LongTerm Behaviour of Fly Ash and Slag Cement Grouts for Micropiles Exposed to a Sulphate Aggressive Medium. Materials 2017, 10, 598. doi:10.3390/ma10060598

40. Keddam, M.; Takenouti, H.; Nóvoa, X. R.; Andrade, C.; Alonso, C. Impedance measurements on cement paste. Cem. Concr. Res. 1997, 27 (8), 1191-1201 DOI: 10.1016/S0008-8846(97)00117-8.

41. Ortega, J. M.; Sánchez, I.; Antón, C.; De Vera, G.; Climent, M. A. Influence of environment on durability of fly ash cement mortars. ACI Mater. J. 2012, 109 (6), 647-656.

42. Ortega, J. M.; Sánchez, I.; Climent, M. A. Durability related transport properties of OPC and slag cement mortars hardened under different environmental conditions. Constr. Build. Mater. 2012, 27 (1), 176-183 DOI: 10.1016/j.conbuildmat.2011.07.064.

43. Duan, P.; Shui, Z.; Chen, W.; Shen, C. Effects of metakaolin, silica fume and slag on pore structure, interfacial transition zone and compressive strength of concrete. Constr. Build. Mater. 2013, 44, 1-6 DOI: 10.1016/j.conbuildmat.2013.02.075.

44. Aköz, F.; Türker, F.; Koral, S.; Yüzer, N. Effects of sodium sulfate concentration on the sulfate resistance of mortars with and without silica fume. Cem. Concr. Res. 1995, 25 (6), 1360-1368 DOI: 10.1016/00088846(95)00128-Y.

45. Al-Dulaijan, S. U. Sulfate resistance of plain and blended cements exposed to magnesium sulfate solutions. Constr. Build. Mater. 2007, 21 (8), 1792-1802 DOI: 10.1016/j.conbuildmat.2006.05.017.

(C) 2018 by the authors; licensee MDPI, Basel, Switzerland. This article is an open access article distributed under the terms and conditions of the Creative Commons Attribution (CC BY) license (http://creativecommons.org/licenses/by/4.0/). 